Erratum

\title{
Erratum to: 'Competitive intramolecular hydrogen bonding formation and excited-state proton transfer reaction in 1-[(diethylamino)-methyl]-2-hydroxy-3-naphthaldehyde' [Chem. Phys. Lett. 382 (2004) 203-209] 岤, 弥
}

Kun-Chan Wu, Yi-Ming Cheng, Yu-Shan Lin, Yu-Shan Yeh, Shih-Chieh Pu, Ya-Hui Hu, Jen-Kan Yu, Pi-Tai Chou *

Department of Chemistry, The National Taiwan University, Taipei 106, Taiwan, ROC

The publisher regrets that during the publication process a mistake was made in the name and e-mail address of one of the authors.
The name Pi-Tai Che and e-mail address cheptc@ ccunix.edu.tw should be written as above; Pi-Tai Chou, e-mail address: chop@ntu.edu.tw.

\footnotetext{
PII of original article S0009-2614(03)02041-4.

解 DOI of original article 10.1016/j.cplett.2003.11.058.

${ }^{*}$ Corresponding author. Fax: +886-52721040.

E-mail address: chop@ntu.edu.tw (P.-T. Chou).
} 